\title{
Implications of Selected Use of Learner's First Language in English Language Teaching
}

\author{
Nan Kang \\ Queen Mary University of London, England, UK \\ Email: nankang1996@163.com
}

\begin{abstract}
This academic essay is an assessed coursework in Approaches and Methods in Language Teaching for taught postgraduate in School of Languages, Linguistics, Queen Mary University of London. This essay seeks to identify the necessity of inclusion of First Language in foreign language teaching and its following positive and negative impacts. Involving Target Language in language lessons is a bright idea due to its cognitive, communicative and social functions, though it might cause a few problems, such as the limited effect on elite students, the inefficient and time- consuming learning process, student's over-reliance of L1. In the end, the essay provides a few teaching suggestions for language teachers.
\end{abstract}

Keywords: language teaching approaches, first language, ELT

\section{Introduction}

There appears to be a growing agreement that the First Language (L1) plays a vital role in English Language Teaching (ELT) classroom suggested by a number of professionals. They believed the use of L1 affects learner's willingness to experiment with English and capabilities of taking more risks when use Target Language (TL). Opponent researchers argued that "students learn the target language 'better' when completely immersed and surrounded by it." (Brooks-Lewis. 2009.) They believe L1 would impede learner's perception and production of TL. In my case, Involving learner's L1 in language classroom is acceptable, as it can aid learners perception and production of the target language. But it is also worthy of serious consideration.

This essay seeks to identify the necessity of inclusion of L1 in foreign language teaching and its following positive and negative impacts. Involving TL in language lessons is a bright idea due to its cognitive, communicative and social functions, though it might cause a few problems, such as the limited effect on elite students, the inefficient and time-consuming learning process, student's over- reliance of L1. In addition, the essay analyzes relevant implications for teaching methodology.

\section{Literature review}

The positive role of L1 in language teaching has been recognized by more and more researchers. According to Ellis (1997), L1 benefits foreign language learner in a general approach. Turnbull \& Dailey-O'Cain (2009) further identified three main functions of L1: cognitive, communicative and social functions. The three play different roles and impact the teaching results positively. First, the cognitive function of L1 can raise learners' awareness of differences and similarities between L1 and L2. (Schweers, 1999), since the sense of rupture in two different language systems seems to be dissolved with the involvement of L1, the two languages are not conflicting at all. Second, involving L1 in language classroom also contains remarkable communicative function as it can facilitate interaction between learners and teachers. Butzkamm (1998) described L1 as a type of "conversational lubricant". Millan (2011) stated that L1 can facilitate and ensure communication between students and teachers. Both of them have noticed the significant function of ML in communication. Third, L1 also contains social function.

However, the related negative outcomes of using FL in ELT should not be skipped. A central issue is learners' overreliance of L1. The International Teacher Training Organization (2007) suggested "the 'scaffolding tool' proposed by sociocultural theory has been demoted to a 'crutch', especially when it is used in early teaching stages, as learners may become over-dependent on L1 in subsequent learning process".

The limited efficiency of L1 use for high-level L2 learners is considered to be another common issue. Kim \& Perraki's investigation (2009) argued when compared with high-level classmates, low-level students appear to benefit more from the use of L1. This is because they "selected more functions for L1 use than those at upper intermediate to advanced level." Therefore, student's L2 learning outcomes are largely depended on their various level of foreign language abilities, not the aid of L1. 
Additional time should also be take into considerations, since providing explanations in two different languages within limited class time would inevitably bring demand for excessive class hours and efforts.

\section{Discussion of possible implications of $L 1$ use in language classroom}

Based on previous researches, below are a few suggestions for language teachers to consider using L1 in appropriate teaching processes.

\subsection{Selecting $L 1$ at specific stages of a lesson}

Teachers are encouraged to use ML in a few certain stages to avoid learner's over-reliance of ML. First, to use the FL is strongly encouraged in the period of peer work. Students may encounter a variety of communicative and comprehensive problems in the process of foreign language learning, using L1 would benefit those learners from clarification from teachers or to teachers.

Also, teachers are suggested to use ML in grammar and vocabulary teaching stage. Students have to perceive the message (what is meant) before they could understand the syntactical transparency eventually (how it is said), thus, L1 is considered as an important 'via medium' in explaining the meaning of vocabularies. Similarly, the using of L1 makes English grammar more accessible to students. Word-for-word translations from L1 to TL can be an economical way to aid learners acquire unfamiliar language.

\subsection{Allocating L1 teaching time reasonably}

L1 should not become the dominant language in the classroom. To achieve this goal, Naves (2009) suggested teachers to allocate at least 50 percent of lesson time in the L2. Also, the proportion of L2 should be increased with time. Class language should include 75 percent of TL with the development of time. In the end part of class, tasks should solely in TL and ML should not be used anymore. In accordance with the increasing language difficulty levels, adequate TL teaching time and learner's interests can be maintained.

\subsection{Making language adjustments based on student's level}

Teachers should take student's language level into consideration when adopt different teaching strategies. It is allowed for low-level students to respond to teacher's L2 question in L1. This will ensure the language class runs smoothly and benefits the classroom management. Correspondingly, teachers should use more TL for high-level students. L1 textbooks or supplementary materials can also be used to provide support in L2 instruction.

\section{Conclusion}

This essay seeks to identify advantage and limitations of the inclusion L1 in foreign language teaching and its implications for language teachers. Involving L1 can have three positive impacts: cognitive, communicative and social functions, which promotes language learning qualities.

However, it can also leads to problems such as wasted time, excessive reliance, limited positive impact on excellent students and possible ineffective learning results. In the end, this essay puts forward three main implications of using L1 in language lessons for teachers. First, teachers should allocate class time reasonably to balance proportions between L1 and TL properly. Second, it is suggested to use L1 at certain teaching stages, such as lesson preparation, vocabulary definition and grammar explanation. Third, teachers should make adjustments based on specific language levels of target student groups.

\section{References}

[1] Brooks-Lewis, K. A. (2009). Adult learners' perceptions of the incorporation of their L1 in foreign language teaching and learning. Applied Linguistics, 30(2), 216-235.

[2] Butzkamm, W. (1998). Code-switching in a bilingual history lesson: the mother tongue as a conversational lubricant. International Journal of Bilingual Education and Bilingualism, 1(2), 81-99.

[3] Ellis, R. (1997). Second Language Acquisition. New York: Oxford University Press.

[4] International Teacher Training Organization. (2007). Using L1 in the TEFL classroom. Available at http://www.teflcertifi catecourses.com/tefl-articles/L1-teflclassroom.html. Accessed 16 December 2018.

[5] Kim,Y. \& Petraki, E. (2009). Students' and Teachers' Use of and Attitudes to L1 in the EFL Classroom. Asian EFL Journal, 11(4), 58-89.

[6] McMillan, B. A. \& Damian J. Rivers, D. J. (2011). The practice of policy: Teacher attitudes toward "English only". System, 39(2), 251-263. 
[7] Naves, T. (2009). Effective content and language integrated learning programmes. In Y. Ruiz de Zarobe and R. M. Jimenez Catalan (eds.). Content and Language Integrated Learning: Evidence from Research in Europe. Bristol: Multilingual Matters.

[8] Schweers, C, W. (1999). Using L1 in the L2 classroom. ENGLISH TEACHING FORUM, 37(2), 6-13.

[9] Turnbull, M. \& Dailey-O'Cain, J., (2009). First Language Use in Second and Foreign Language Learning. Bristol: Multilingual Matters. 